\title{
Management of peri-ovarian hematoma following oocyte retrieval in a pooling cycle IVF: Case report
}

\author{
Garima Sachdeva ${ }^{1}$, Devi R ${ }^{1}$, Kamini A Rao ${ }^{1}$, Madhuri Vidyashankar $\mathrm{P}^{1}$ \\ ${ }^{1}$ Department of Reproductive Medicine, Milann, Bangalore, India
}

\begin{abstract}
Here we report a case of peri-ovarian hematoma following ovum pick-up in a patient in a pooling cycle IVF (in vitro fertilization). We have attempted to discuss the possible mechanisms for the development of hematoma in such patients, the common clinical presentation, monitoring, and management of these cases. The decision to operate or to manage conservatively forms an important aspect of managing such patients. This case report can help to keep the clinicians alert while managing this subgroup of patients.
\end{abstract}

Keywords: IVF, hematoma, OPU, ultrasound, laparoscopy

\section{INTRODUCTION}

Transvaginal ultrasound-guided oocyte retrieval is the safest and most widely used method of ovum pick-up (OPU) worldwide. Bleeding post-OPU is very rare, with a reported prevalence of vaginal bleeding and intra-abdominal/intraperitoneal bleeding post pick up of around $0.01 \%$ and $0.23 \%$, respectively (Levi-Setti et al., 2018).

Here we discuss a case of peri-ovarian hematoma postOPU, which required laparoscopy due to failed conservative management, with progressively increasing hematoma size and fall in hemoglobin levels.

\section{CASE REPORT}

A 34-year-old woman with a history of primary infertility of 7 years visited our infertility center. She had a history of tuberculosis, for which anti-tuberculosis treatment (AKT4) was given. Diagnostic hystero-laparoscopy and chromopertubation were suggestive of bilateral patent tubes. Endometrial biopsy was positive for mycobacterium tuberculosis (TB-PCR) and she was treated again with AKT4.

The decision for in vitro fertilization (IVF) was made because of multiple failed TI/IUI cycles, high FSH (10.49 $\mathrm{IU} / \mathrm{ml})$, low AMH $(0.41 \mathrm{ng} / \mathrm{ml})$, and male factor (teratozoospermia and high DNA fragmentation index of 25\%). The first OPU was done in 2019 using a mild stimulation protocol which was uncomplicated and 2- good quality blastocysts were formed.

The second ovum pick-up was planned after 1 month. We used a mild stimulation protocol (Letrozole and HMG $150 \mathrm{IU})$. The right ovary did not respond to stimulation. We retrieved two oocytes from the left ovary using a double lumen needle and only a single puncture was performed and two flushes each of 2 ccs were done for each follicle.

On day 3 post pick up, the patient developed complaints of mild abdominal pain. Her vitals were stable and her abdomen was soft. Ultrasound revealed a left ovarian hematoma $4.48 \mathrm{~cm} \times 4.31 \mathrm{~cm} \times 2.86 \mathrm{~cm}$ and hemorrhagic free fluid around the left ovary with a maximum vertical pocket- $2.6 \mathrm{~cm}$ (Figure $1 \mathrm{~A}$ ). Her right ovary measured 2.3 $X 1.5 \times 2 \mathrm{~cm}$ and the left ovary measured $4.4 \times 3.7 \times 3$ $\mathrm{cm}$. Two corpora lutea noted in the left ovary and its vascularity was well maintained. Her hemoglobin was $10 \mathrm{mg} /$ $\mathrm{dl}$, which was similar to her baseline hemoglobin. Her renal function test (creatinine- $0.6 \mathrm{mg} / \mathrm{dl}$ ), bleeding time ( $2 \mathrm{~min}$ $30 \mathrm{sec}$ ), clotting time (5 minutes), and urine culture were within normal limits.

On day 8 , post-pick-up the intensity of abdominal pain increased and the patient developed tenesmus and pain during micturition. Upon examination, she was afebrile, she had a tenderness in the left iliac fossa, but no guarding or rigidity were present. She was hemodynamically stable. Her ultrasound scan revealed an increase in the size of the hematoma $(5.3 \mathrm{~cm} \times 5 \mathrm{~cm} \times 3.5 \mathrm{~cm}$ ) (Figure 1B) and a slight drop in hemoglobin $(9.7 \mathrm{mg} / \mathrm{dl})$. There was neutrophilia $(70 \%)$ and the patient was started on intravenous antibiotics. Daily monitoring of vitals, ultrasound findings, and alternate-day blood counts was done, and intravenous antibiotics were continued.

Day 11 post-pick-up, an ultrasound revealed an increase in the hematoma size $(9.4 \mathrm{~cm} \mathrm{X} 6 \mathrm{~cm} \times 5.7 \mathrm{~cm})$ (Figure 1D) and a further drop in hemoglobin $(8.7 \mathrm{mg} /$ dl). Table 1 shows changes in the ultrasound and clinical parameters post-pick-up. The decision for laparoscopy was made because of it.

On laparoscopy hemoperitoneum of $100 \mathrm{cc}$ was noted, which was evacuated. An organized clot of $10 \times 8 \mathrm{~cm}$ was noted around the left ovary extending to the pouch of Douglas and right ovary, also evacuated. On evacuating the clot, a bleeder was identified at the left ovarian puncture site; hemostatic sutures were taken (Figure 2D). Figure 2 demonstrates intraoperative laparoscopy findings. The patient was treated with a course of oral antibiotics and oral hematinics. The patient's symptoms improved in the postoperative period. There was a progressive decrease in the size of the hematoma and it almost disappeared on day 28 post-laparoscopy. Table 2 and Figure 3 demonstrate ultrasonographic and hematological findings in the postoperative period.

\section{DISCUSSION}

This patient presented with abdominal pain, tenesmus, and pain during micturition. Her symptoms were not correlating with the pick-up day findings, which triggered us to do an urgent scan, which revealed a peri-ovarian hematoma.

The various proposed mechanisms for intra-abdominal hematoma post-OPU include multiple punctures of the vaginal vault and the ovaries. The enlarged overstimulated ovaries especially in the lean PCOS (polycystic ovarian syndrome) patients proved to be a higher risk (Liberty et al., 2010). The other possible reasons include deranged coagulation profile, low platelet count, patient on any anticoagulants or on antiplatelets for some medical reason (Nouri et al., 2014). Rupture of the endometriotic cysts or hemorrhagic cysts is another possible cause (Lee et al., 2017). The previous history of pelvic tuberculosis, pelvic inflammatory disease, previous abdominopelvic surgeries, or previous OPU can result in neovascularization, and these fragile vessels can rupture resulting in hematoma in a subsequent pick up (Zhen et al., 2010).

The possible reasons for the peri-ovarian hematoma in this patient could be recent OPU, and history of tuberculosis, which could have resulted in neo-vascularization, and 


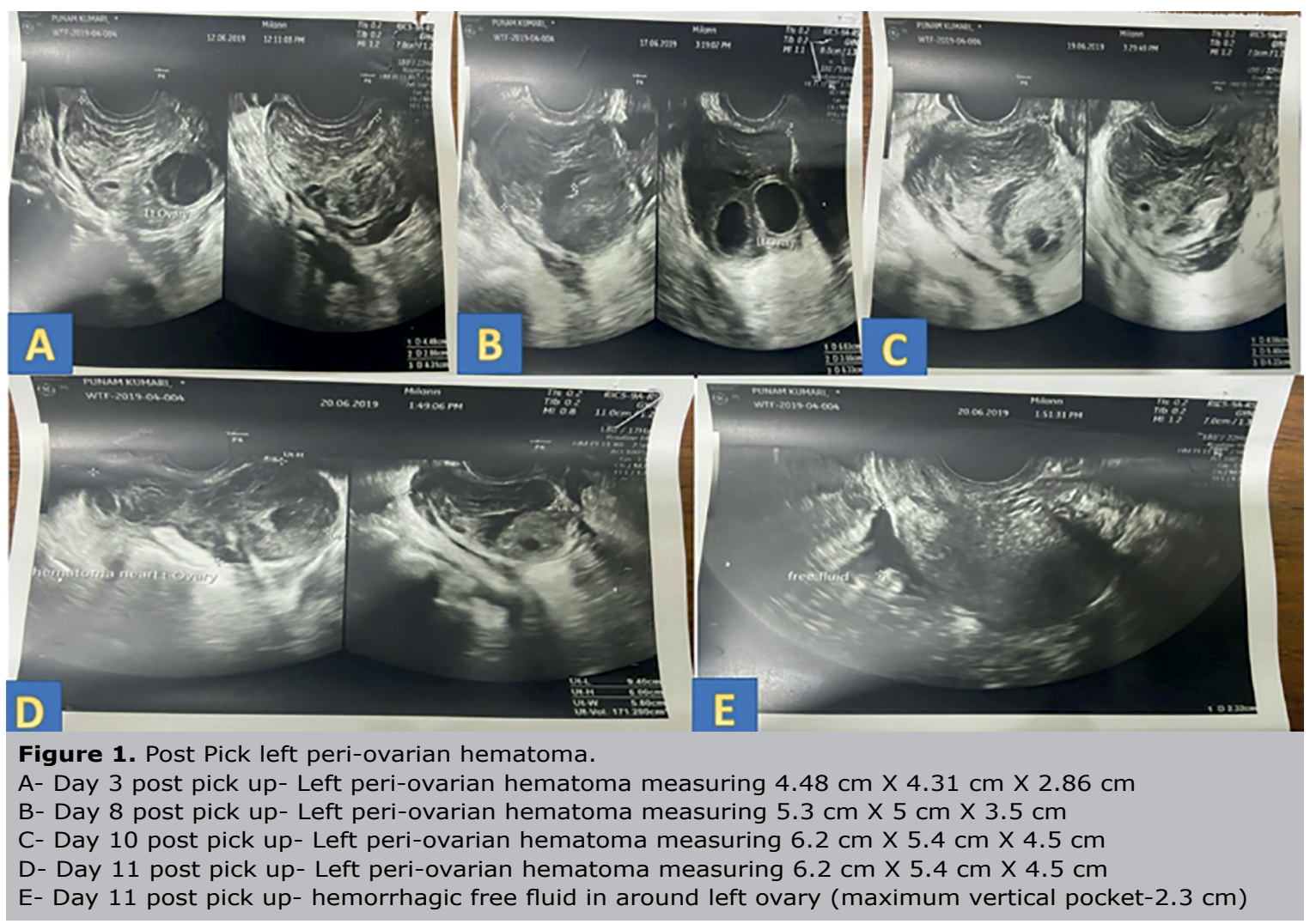

\begin{tabular}{|c|c|c|c|c|c|c|}
\hline \multirow{2}{*}{$\begin{array}{l}\text { POST OVUM } \\
\text { PICK UP DAY }\end{array}$} & \multirow{2}{*}{$\begin{array}{c}\text { Ultrasound findings } \\
\begin{array}{c}\text { Left peri-Ovarian } \\
\text { Hematoma }\end{array}\end{array}$} & \multirow{2}{*}{ 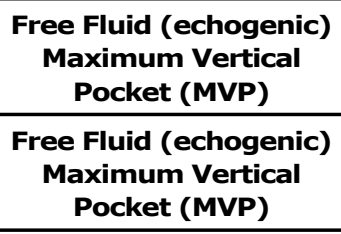 } & \multicolumn{4}{|c|}{ Counts } \\
\hline & & & $\begin{array}{c}\text { Hemoglobin } \\
(\mathbf{g} \%)\end{array}$ & 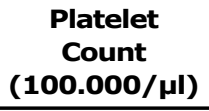 & $\begin{array}{l}\text { Total } \\
\text { cells/ } \\
\mu \mathrm{Il}\end{array}$ & $\begin{array}{c}\text { Differential } \\
\text { Neutrophil -N } \\
\text { Lymphocytes -L }\end{array}$ \\
\hline DAY 3 & $4.48 \times 4.31 \times 2.86 \mathrm{~cm}$ & MVP-2.6 cm & 10 & 1.4 & 10100 & $\begin{array}{l}\text { N70 } \\
\text { L24 }\end{array}$ \\
\hline DAY 8 & $5.3 \times 5.0 \times 3.5 \mathrm{~cm}$ & MVP-2.6 cm & 9.7 & 1.4 & 10300 & $\begin{array}{l}\text { N70 } \\
\text { L24 }\end{array}$ \\
\hline DAY 10 & $6.2 \times 5.4 \times 4.5 \mathrm{~cm}$ & MVP-1.6 cm & 8.9 & 1.4 & 8100 & $\begin{array}{l}\text { N71 } \\
\text { L24 }\end{array}$ \\
\hline DAY 11 & $9.4 \times 6.0 \times 5.7 \mathrm{~cm}$ & MVP-2.3 cm & 8.7 & 1.5 & 7600 & $\begin{array}{l}\text { N70 } \\
\text { L21 }\end{array}$ \\
\hline
\end{tabular}

rupture of these fragile vessels might have resulted in the hematoma. In addition, the short duration between two cycles of pick-up could have added to this complication.

The Conservative approach is the first-line management in a hemodynamically stable patient as it saves the patient from another surgery or need for oophorectomy (Nouri et al., 2014). However, while doing so, one should keep a stringent watch on the vitals, symptoms, hematoma size, hemoglobin, and blood counts. Moreover, one should not postpone the surgery for too long if the patient is not improving as it can lead to life-threatening conditions like hemorrhagic shock, disseminated intravascular coagulation, and sudden death (Liberty et al., 2010). In this case, once we realized that the patient is not responding and there is a progressive increase in the hematoma size with a drop-in hemoglobin, the decision for surgery was made. Since the patient was hemodynamically stable, laparoscopy was performed instead of open surgery. 


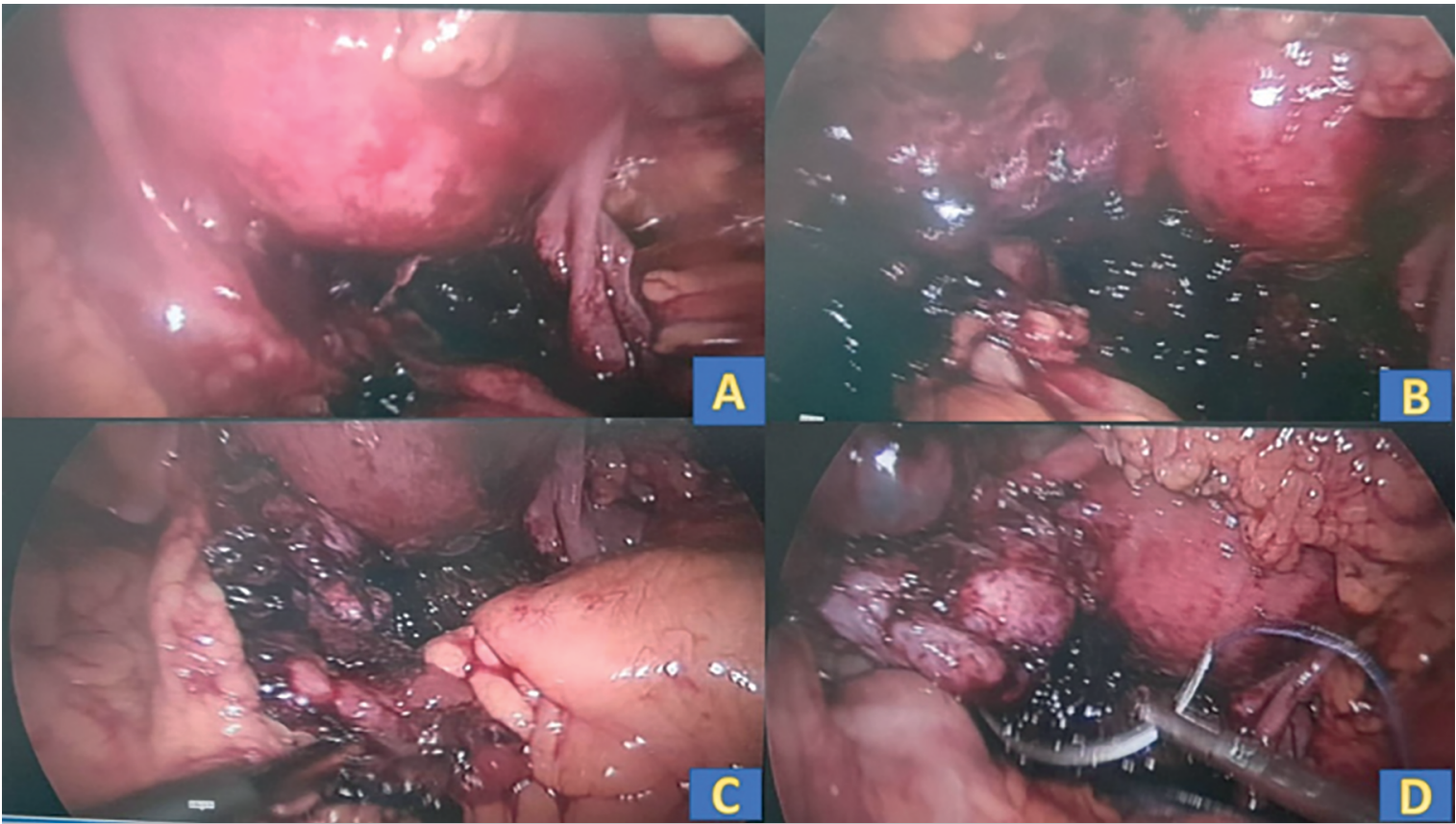

Figure 2. Intra-operative laparoscopy findings.

2A, 2B, 2C-Organized clot and hemoperitoneum noted at laparoscopy

2D- blood trickle from the left ovarian surface, hemostatic sutures taken

Table 2. Ultrasonographic and hematological findings in the post-laparoscopic period.

\begin{tabular}{|c|c|c|c|c|c|c|}
\hline \multirow{2}{*}{$\begin{array}{l}\text { POST OVUM } \\
\text { PICK UP DAY }\end{array}$} & Ultrasound findings & $\begin{array}{l}\text { Free Fluid } \\
\text { (echogenic) } \\
\text { Maximum }\end{array}$ & \multicolumn{4}{|c|}{ Counts } \\
\hline & Left peri-Ovarian Hematoma & Free Fluid (FF) & $\begin{array}{c}\text { Hemoglobin } \\
(\mathbf{g} \%)\end{array}$ & $\begin{array}{c}\text { Platelet } \\
\text { Count } \\
(100.000 / \mu \mathrm{l})\end{array}$ & $\begin{array}{l}\text { Total } \\
\text { cells/ } \\
\mu \mathrm{l}\end{array}$ & $\begin{array}{c}\text { Differential } \\
\text { Neutrophil -N } \\
\text { Lymphocytes -L }\end{array}$ \\
\hline DAY 3 & $3.68 \times 3.10 \times 1.80 \mathrm{~cm}$ & NO FF & 10 & 1.8 & 8100 & $\begin{array}{l}\text { N60 } \\
\text { L30 }\end{array}$ \\
\hline DAY 16 & $3.11 \times 2.97 \times 1.805 \mathrm{~cm}$ & NO FF & & & & \\
\hline DAY 10 & $2.7 \times 2.6 \times 1.20 \mathrm{~cm}$ & NO FF & 10.4 & 2.82 & 4100 & $\begin{array}{l}\text { N58 } \\
\text { L28 }\end{array}$ \\
\hline DAY 16 & $2.0 \times 1.1 \times 1.20 \mathrm{~cm}$ & NO FF & & & & \\
\hline DAY 28 & NO HEMATOMA & NO FF & & & & \\
\hline
\end{tabular}

\section{CONCLUSION}

Ovarian hematoma post-OPU is a rare complication. Post-pick-up abdominal pain, tenesmus, and pain during micturition can be important indicators of a pelvic hematoma. Previous OPU and tuberculosis may result in neovascularization and these fragile vessels can rupture during subsequent OPU resulting in intra-abdominal bleeding. A Conservative approach with close monitoring forms the first-line management in hemodynamically stable patients. However, if the patient does not improve or worsens with conservative management, surgery becomes imminent to prevent catastrophic complications.

\section{CONFLICTS OF INTEREST}

Authors display no conflict of interest. 


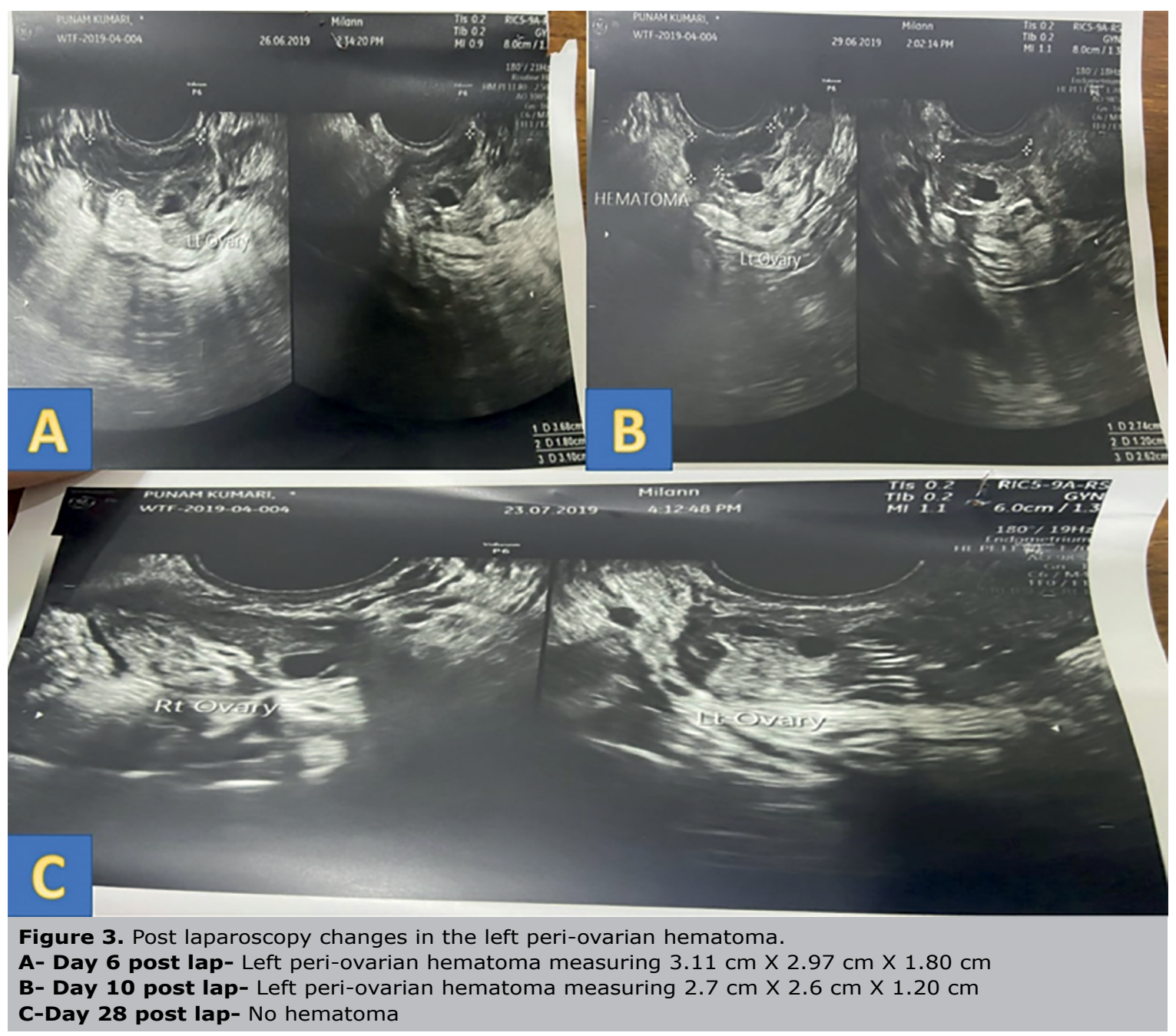

\section{Corresponding author:}

\section{Garima Sachdeva}

Department of Reproductive Medicine

Milann - The Fertility Center

Milann, Bangalore. India

E-mail: gsachdeva25@gmail.com

ORCHID ID: https://orcid.org /0000-0003-0542-2168

\section{REFERENCES}

Lee MS, Moon MH, Woo H, Sung CK, Jeon HW, Lee TS. Ruptured Corpus Luteal Cyst: Prediction of Clinical Outcomes with CT. Korean J Radiol. 2017;18:607-14. PMID: 28670155 DOI: 10.3348/kjr.2017.18.4.607

Levi-Setti PE, Cirillo F, Scolaro V, Morenghi E, Heilbron F, Girardello D, Zannoni E, Patrizio P. Appraisal of clinical complications after 23,827 oocyte retrievals in a large assisted reproductive technology program. Fertil Steril. 2018;109:1038-43. e1. PMID: 29871795 DOI: 10.1016/j.fertnstert.2018.02.002
Liberty G, Hyman JH, Eldar-Geva T, Latinsky B, Gal M, Margalioth EJ. Ovarian hemorrhage after transvaginal ultrasonographically guided oocyte aspiration: a potentially catastrophic and not so rare complication among lean patients with polycystic ovary syndrome. Fertil Steril. 2010;93:874-9. PMID: 19064264 DOI: $10.1016 / j . f e r t n-$ stert.2008.10.028

Nouri K, Walch K, Promberger R, Kurz C, Tempfer CB, Ott J. Severe haematoperitoneum caused by ovarian bleeding after transvaginal oocyte retrieval: a retrospective analysis and systematic literature review. Reprod Biomed Online. 2014;29:699-707. PMID: 25444503 DOI: 10.1016/j. rbmo.2014.08.008

Zhen X, Qiao J, Ma C, Fan Y, Liu P. Intraperitoneal bleeding following transvaginal oocyte retrieval. Int J Gynaecol Obstet. 2010;108:31-4. PMID: 19879578 DOI: 10.1016/j. ijgo.2009.08.015 